DOI: 10.17805/zpu.2016.4.16

\title{
Возможности повышения результативности социального управления брендинговой деятельностью
}

\author{
Т. Л. БАГАЕВА \\ (КИЕВСКИЙ ГОСУДАРСТВЕННЫЙ УНИВЕРСИТЕТ ИМ. ТАРАСА ШЕВЧЕНКО, УКРАИНА) \\ И. Я. РОЖКОВ \\ (МОСКОВСКИЙ ГОСУДАРСТВЕННЫЙ ИНСТИТУТ МЕЖДУНАРОДНЫХ ОТНОШЕНИЙ \\ (УНИВЕРСИТЕТ) МИД РОССИИ)
}

Деятельность различных компаний в области брендинга перманентно усиливается, его коммуникации все шире применяются в самых различных направлениях человеческой деятельности, при этом высокий уровень расходов настоятельно требует их оптимизации. В условиях неопределенности результатов и рискогенности брендинговой деятельности данную задачу можно решить, дополнив традиционные маркетинговые подходы к управлению брендингом инновационными, основанными на достижениях современной социологии.

Анализ зарубежной и отечественной научной литературы, посвященной проблемам брендинга, показал, что его многочисленные исследования в основном сфокусированы на управленческих, бихевиористских, психологических, коммуникативных аспектах. Практически во всех этих работах доминирует маркетинговый подход, в то время как социологический применяется ограниченно, что не дает возможности исследовать брендинг комплексно.

Вместе с тем в социуме происходят радикальные изменения, которые нельзя игнорировать. Чтобы брендинговая деятельность стала адекватной новому состоянию общественной среды, авторы предлагают рассматривать брендинг как социальную систему, проходящую в своем развитии несколько фаз, способную к самоорганизации и саморазвертыванию. В такой системе функционирует множество социальных акторов и возникает риск их выхода из-под контроля управляющего субъекта. В то же время его авторитаризм может привести к негативным результатам, так как нередко тормозит внедрение инноваций, способствующих развитию системы.

Данные факторы предопределяют применение в брендинге, в отличие от традиционного, нового управленческого принципа, представляющего собой сочетание линейного и нелинейного управления, включающего акупунктурное воздействие на рискогенные точки системы - социальных акторов, вовлеченных в процессы брендинга.

Ключевые слова: бренд; брендинг; социальная система брендинга; смыслы; управление смыслами; аутопойесис; саморазвертывание; самоорганизация; интуиция; акупунктурное воздействие

\section{BВЕАЕНИЕ}

】 сследователи брендинга - деятельности, связанной с продвижением объектов именованиями) предпочтительного отношения к ним, высокой репутации, лидирующего положения в целевых аудиториях, получения либо поддержания или усиления статуса бренда, - сталкиваются с проблемой, связанной с необходимостью радикального повышения результативности данной деятельности. Запрос практики в этом направлении пока еще недостаточно удовлетворен наукой, от которой потребовались соответствующие современным реалиям знания и инновационные подходы к управлению брендингом, основанные на переосмыслении особенностей его функционирования. Цель данной статьи: попытаться взглянуть на брендинг в новом ракурсе и предложить новое видение путей поиска перспективных механизмов управления его процессами. 


\section{БРЕНАИНГ В СОВРЕМЕННЫХ УСАОВИЯХ}

Объектами брендинга, кроме традиционных (товаров, услуг, компаний), все чаще становятся территории (страны, регионы, города, места, представляющие особый интерес для туризма или рекреации), партии, личности (политики, общественные деятели, представители научной, культурной и других сфер деятельности), научные, образовательные, спортивные учреждения, некоммерческие организации, события и пр.

Сегодня подавляющая часть общемировых расходов на коммуникации в рекламнокоммуникационной сфере, которые, согласно данным лидирующего в этой сфере холАинга WPP Group, накануне начавшегося в 2008 г. мирового финансового кризиса достигали 1 трлн долл., но к 2014 г. снизились из-за него до 916,4 млрд долл. (WPP. Thirty Years ..., 2015: 90), направляются на создание, продвижение, поддержание, усиление и капитализацию брендов. Эти расходы поглощают существенную часть бюджетов большинства производителей товаров и услуг. В 2014 г. у традиционно лидирующей в отчислениях на рекламно-коммуникационную деятельность транснациональной корпорации Procter \& Gamble они составили 2,6 млрд долл., а у занявших второе и третье места General Motors и AT\&T - по 1,6 млрд (там же: 89).

Колоссальные затраты на брендинг заставляют искать пути его оптимизации, в первую очередь путем повышения эффективности управления. Этот поиск связан еще и с тем, что внедряемые в общественную среду бренды, обладающие мощным идеологическим потенциалом, не только стимулируют рыночную активность компаний, формируют взгляды и поведенческие паттерны индивидов, но и влияют на состояние общественной среды. Обращение к брендингу, имеющему в своем арсенале комплекс апробированных коммуникационных технологий, развитых систем коммуникативного воздействия на общество и инструментов социального контроля над данным воздействием, дает возможность прогнозировать и предупреждать социальные следствия, в том числе латентные, реализовывать социально значимые гуманитарные проекты.

Так как брендинг применяется в самых различных областях человеческой деятельности и в ней принимает участие большое количество социальных акторов, каждый из которых имеет свои взгляды, интенции и профессиональные возможности, мы определяем брендинг как метасистему социального управления коммуникациями при продвижении практически любых объектов в конкурентной среде (Рожков, Багаева, 2012: 65).

\section{СОЦИОАОГИЧЕСКИЕ ПОАХОАЫ К ИССАЕАОВАНИЮ БРЕНАИНГА}

В последние десятилетия компании, занимающиеся коммуникационной деятельностью, пополнились солидным корпусом профессионалов в областях брендинга, рекламы, политтехнологий, маркетинга, маркетинговых коммуникаций, связей с общественностью, отношений с властными структурами и инвесторами, корпоративной социальной ответственности, аналитиками, которые были востребованы в сфере бизнеса, системе органов государственного управления, политической сфере. В настоящее время многие из этих специалистов вовлечены в реализацию коммуникационных технологий информационных войн, суть которых в продвижении смыслов, сконцентрированных в бренд-имиджах, несущих социально значимую идеологическую информацию об объектах, участвующих в этих войнах, событиях, явлениях, им сопутствующих. 
Теоретическая разработка проблем брендинга и приложение их результатов, особенно к деловой сфере, стали темой многочисленных трудов исследователей и практиков, прежде всего в области маркетинга и маркетинговых коммуникаций.

Анализ западной научной литературы позволил нам выделить ключевые подходы к пониманию брендинга, в том числе: экономический (Borden, 1964); хронологический (Goodyear, 1996); когнитивньй (Franzen, Bouwman, 2001); коммуникативньй (Hatch, Schultz, 1997); структурный (Chernatony, Dall'Olmo, 1998); основанныий на теории потребительского выбора (Keller, 2003); «очеловечивающий (Aaker, 1997); этнографический (Muniz, O'Guinn, 2001) и др. Изучение референтных публикаций российских и украинских исследователей убеждает в том, что и их подходам к брендингу присуща четкая фокусировка на его конкретных аспектах - управленческих, бихевиористских, психологических, коммуникативных, культурологических и др., причем, в подавляющем большинстве эти исследователи анализируют отдельные составляющие брендинга и во многом опираются на западные источники. Характерно, что практически все авторы рассматривают брендинг в рамках маркетинга или соотносят с ним свои исследования.

Маркетинговая доминанта прослеживается и в работах социологов, прямо или косвенно затрагивающих проблемы брендинга, например в наиболее известных российских трудах, принадлежащих $\Lambda$. Н. Федотовой, Ф. И. Шаркову, которые отдельно рассматривают с социологической точки зрения рекламу (Федотова, 2014), связи с общественностью, массовые коммуникации (Федотова, 2003; Шарков, 2012). Ни одна из известных нам работ не позволяет представить целостную картину социологии брендинга.

Вместе с тем в последнее время социум столкнулся с беспрецедентными вызовами. Интенсифицировались и убыстрились социально-экономические процессы. Практически во всех сферах человеческой деятельности резко ужесточилась конкуренция и повысилась степень неопределенности ее результатов и рискогенности. В этих новых условиях стала очевидной необходимость ревизии традиционных подходов к управлению брендингом, поиск управленческих инноваций, выходящих за рамки маркетинга, использующих наработки социологической науки. Тем более что благодаря научно-техническим достижениям, в первую очередь связанных с компьютеризацией и особенно с развитием социальных сетей в Интернете, для брендинга открываются все новые и новые перспективы как деятельности, функционирующей прежде всего на основе социальных технологий.

\section{СОЦИААЬНЫЕ ПРЕАПОСЫАКИ ИННОВАЦИЙ \\ В БРЕНАИНГЕ}

О состоянии, трансформации и необходимости инноваций в представляющей собой основу брендинга рекламно-коммуникационной сфере говорят и пишут многие специализирующиеся в ней профессионалы. Если подытожить смысл появившихся в последние годы публикаций, выступлений, а также заявлений известных теоретиков и практиков, среди основных социально значимых приоритетов развития брендинга можно выделить следующие:

- стремление с помощью брендов путем интерактивного диалога с целевыми аудиториями решать актуальные для них социальные проблемы;

- создание брендов с ярко выраженной социальной миссией;

- активизация коммуникационной деятельности в киберпространстве; 
- рост значения социальной ответственности брендов и брендинга;

- совместный поиск участниками брендингового процесса компромиссных форм сотрудничества, сочетающих интересы бизнеса и общества.

В конце XIX в. проявились тенденции, ранее находившиеся в латентном состоянии, например, признаки замещения «эры экспозиции» (наглядного представления решения брендом социальных проблем его пользователя) «эрой шоу-бизнеса». 3. Бауман писал по этому поводу: «Зрелища пришли на место наблюдению, не потеряв дисциплинарной власти своего предшественника. Подчинение... теперь достигается посредством соблазна и обольщения, а не принуждения и оказывается под маской осуществления свободной воли, а не проявляется в форме внешней силы» (Бауман, 2008: 94).

Весьма интересные наблюдения, которые можно связать с необходимостью изменений в подходах к реализации брендинговой деятельности, приводит Н. Бариле. В частности, этот автор обращает внимание на интенсификацию процесса демассификации и активизацию стремления потребителя к освобождению от манипулирующей рекламы, его становление в качестве деятельного просьюмера ( «любителя-знатока»), (Бариле, 2015: 138), выступающего в брендинговой деятельности в качестве социального актора, что во многом стало возможными благодаря развитию социальных сетей в Интернете.

С. А. Кравченко отмечает, что одной из коллективных реакций на новации неопределенности в развитии современных обществ становится играизация. Внедрение принципов игры, эвристических элементов в прагматические жизненные стратегии позволяет индивидам посредством саморефлексии достаточно эффективно выполнять основные социальные роли, адаптироваться к постоянно меняющемуся обществу, его нелинейной динамике. В характерных для современности условиях неопределенности и хаоса образуется новый тип рациональности. Активно проявляется фактор конструирования и поддержания виртуальной реальности (Кравченко, 2002: 143-155). Бренды помогают индивидам в их самоидентификации, исполнении выбранных ими ролей.

Усилилась тенденция так называемого тотального брендирования (total branding), интегрирующего маркетинг, связи с общественностью, координирующего процессы формирования бренд-имиджа и управления им, рекламы, событийных акций и т. А.

Брендинг все активнее внедряется в общественное пространство, и при этом в контенте сообщений о бренде эксплуатируются факторы, характеризующие ценности, ожидания, предпочтения людей, формируя в общественной среде «мир эмоций и отношений».

Широкое распространение социальных медиа привело к переносу некоторых процессов, доказавших свою результативность в рыночной сфере, в частности неконвенционального маркетинга (доверительного, партизанского, вирусного и т. А.), в область цифровой коммуникации.

Отмечается расширение применения манипулятивных коммуникационных технологий, включающих: дезинформацию, слухи, фейкизацию, фактоиды, неконкретность, троллинг, создание «параллельного мира» с новыми персонизирующими политические, эстетические, потребительские идеалы героями, сторителлинг, сакрализацию, блеф, формирование иллюзии объективности, вытеснение альтернативных точек зрения в «информационное гетто», сценарные практики, перенаправление активно- 
сти целевой аудитории, осуществление действий, приводящих конкурента к расходованию людских, материальных и временных ресурсов и т. А.

Если традиционно бренды пополняли опыт потребителя, то теперь произошел поворот к мобилизации эмоций как соревновательного ресурса на мировом рынке идентичности. С одной стороны, воображение потребителя насыщено мировыми брендами, являющимися не только предметами потребления, но и системами символического аффективного обмена, с другой - он становится жертвой кражи идентичности. Потребителя уже нельзя рассматривать в рамках предзаданных социальных категорий, завершенной идентичности. Он полиидентичен - противоречивый субъект, некий «субъект-сообщество» (Бариле, 2015: 141).

Нередко приверженность бренду становится предлогом для «социального исключения», создания специфических сообществ (байкеров, болельщиков, политических объединений и т. д.), представители которых переживают, с их точки зрения, моменты «подлинной жизни», при этом часто проявляется их альтер эго - негативная проекция идентичности. Эмоции, вызываемые сообщениями, идущими от внешней среды, и воспринимаемые через органы чувств, в том числе сообщениями о бренде, как показал Б. Шмитт в своем исследовании эмпирического маркетинга (Шмитт, 2001), способны переформатировать восприятие людьми окружающей действительности. Поэтому наблюдается еще одна тенденция - все большее «вовлечение в бренд» индивидов, стремление к включению в этот процесс всех их органов чувств с целью сформировать предпочтительное отношение к объекту, продвигаемому в конкурентном пространстве.

На фоне сегодняшних и грядущих метаморфоз, радикально меняющих брендинговую деятельность, эксперты прогнозируют существенное перемещение средств, идущих на внедрение, поддержание и усиление брендов, из традиционных областей рекламно-коммуникационной сферы в области, где брендинг реализуется непосредственно в общественной среде.

Беспрецедентное усложнение его, а также конкурентного пространства, в котором функционируют бренды, привело к существенному переосмыслении возможностей маркетингового подхода. Еще в 1960-х годах Т. Аевитт отмечал, что исследования маркетинга (конъюнктурные, сегментационные, конкурентные, медиаанализ) представляют собой «взгляд назад». Они основываются на изучении того, что было и что стало, в то время как необходимо «смотреть вперед». (Иевитт, 2001: 11-34). Маркетинг недостаточно учитывает социальную составляющую брендинга, несмотря на постоянное появление в социуме новых тенденций.

\section{СОЦИААЬНАЯ СИСТЕМА БРЕНАИНГА}

На фоне существенных сдвигов, происходящих в общественной среде, в том числе предопределенных научно-техническими достижениями, брендинг предстает перед исследователями в новом ракурсе - в виде сложной, развивающейся во времени социальной системы. Наше утверждение, что брендинг в процессе своего развития формирует систему, видится корректным, поскольку она представляет собой целостный объект, состоящий из элементов, находящихся во взаимных отношениях, формирующих ее структуру (Керимов, 1998: 788).

Полагая систему брендинга социальной, мы разделяем позицию Т. Парсонса, Э. Шилза, А. Олдса, считающих подобные системы таковыми, так как они являются системами мотивированного действия, организующимися вокруг отношений социаль- 
ных акторов друг к другу и определяются как множество элементов (индивидов, групп, общностей), находящихся во взаимодействиях и отношениях, образующих единое целое (Парсонс, Шилз, Олдс, 2002: 460-461).

Такая система при взаимодействии с внешней средой способна изменять свою структуру, представляющую, как это имеет место в системе брендинга, сеть упорядоченных и взаимообусловленных элементов, коммуницирующих друг с другом и с данной средой.

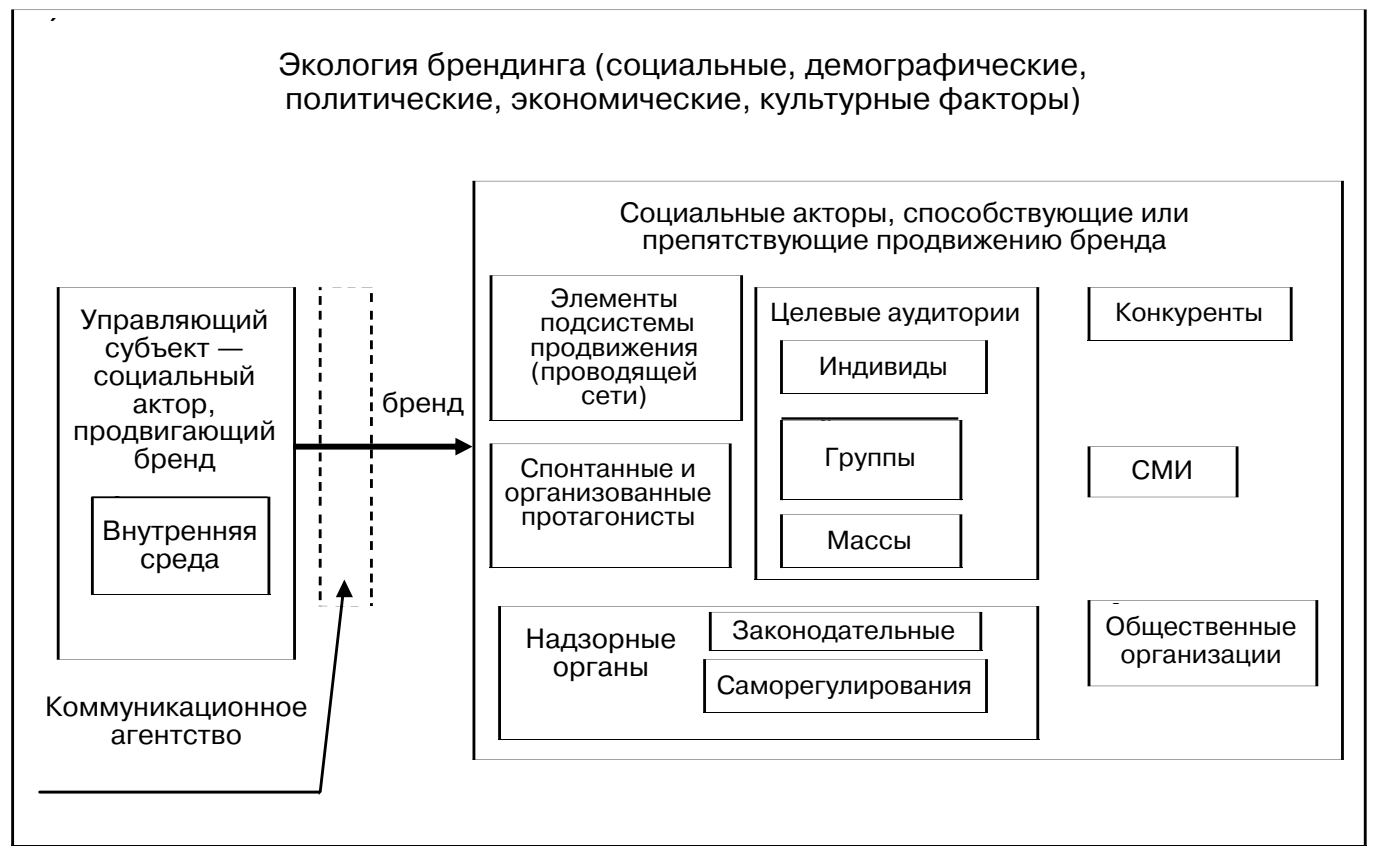

Типовая структура системь брендинга

Conventional structure of a branding system

Внедряясь путем коммуникаций бренда в свое окружение, система брендинга развивается во времени и пространстве. В какой-то момент в ней начинают действовать внутренние «незапланированные» процессы - силы, обусловливающие ее саморазвитие ( «аутопойесис»). Одновременно с развитием система сталкивается с повышением степени риска. Ее развитие может затормозиться, пойти вспять, система даже может погибнуть.

\section{АИНАМИКА СИСТЕМЫ БРЕНАИНГА}

Аинамика развития системы брендинга метафорически может быть уподоблена расширяющемуся шару, с той разницей, что она проходит несколько фаз, переходы между которыми предопределяются количественным накоплением факторов, способствующих качественной трансформации восприятия объекта в социальной среде в результате коммуникации бренда с этой средой и изменений, происходящих в самой системе под воздействием внутренних и внешних, как прогнозируемых, так и непрогнозируемых факторов. 
Первая фраза - внедрение продвигаемого объекта в конкурентное пространство, инициатором, организатором и координатором которого является управляющий субъект. Социальная ценность объекта, предопределяющая его принятие или непринятие внешней средой, является идеологическим ядром формирующейся системы - смыслом, который транслируется на всех ее уровнях и во внешнее пространство. Аанное ядро представляет собой совокупность онтологем, опосредующих контакт участвующих в этом продвижении социальных акторов с трансцендентной реальностью.

Смысл, лежащий в основе сообщения о продвигаемом объекте, формирует коммуникационный посыл, который может обладать способностью пройти через защитные механизмы кодирования, означивания, через призму этических и культурных ценностей и норм индивидов, внести изменения в их социальную жизнь, миропонимание, социальные связи.

Вторая фаза - формирование системы брендинга. На этой стадии отрабатывается и оптимизируется ее структура, налаживаются коммуникации, включая обратные связи, между ключевыми акторами брендингового процесса.

Третья фаза - обретение объектом статуса бренда. Внедрение коммуникаций системы брендинга в социальное пространство, которое пронизано собственными коммуникациями, обеспечивающими движение разнообразных смыслов, может на них повлиять. Когда объект, стремящийся к статусу бренда, внедряется в это пространство, представляющее собой совокупность систем, резистентных по отношению к грозящим им изменениям, это внедрение принимается, если оно согласуется со структурой более высокого уровня; в противном случае оно отвергается. Принятие смыслов, транслируемое объектом, становящимся брендом, зависит от проблем социума и, соответственно, от его обострившихся, но не реализованных потребностей.

Четвертая фаза - расширение, усложнение системы (экспансия бренда на новые географические пространства, в новые целевые аудитории, приобретение им новых функций и т. А.) и проявление в ней хаотических и аутопойетических явлений.

Плтая фаза - усиление влияния на систему процессов аутопойесиса, что приводит к ее самореференции и саморазвитию.

С каждой фазой повышается степень воздействия системы на социум и рискогенность действий социальных акторов (в том числе управляющего субъекта), вовлеченных в процессы брендинга.

\section{ОПТИМИЗАЦИЯ УПРАВАЕНИЯ БРЕНАИНГОМ}

На первых этапах развития системы брендинга управление ею удовлетворяется традиционными технологиями маркетинга. Затем, для предупреждения «разбалансировки» такой системы, потенциально или реально сталкивающейся с хаосом и неопределенностью результатов исполнения ее функций вследствие осознанных или не осознанных действий социальных акторов, функционирующих внутри системы, а также внешних воздействий (политических, экономических, социокультурных факторов), требуется системное «гибридное» управление, сочетающее кинетическую активность (физические воздействия - экономические, организационные) и некинетическую (психологические и социальные воздействия). Суть такого управления - в достижении оптимального состояния системы, ориентированности на поиск «базовой модели влияния», способной мультиплицироваться в различных коммуникационных операциях, осуществляемых в общественной среде. 
Императивом нового онтологического базиса развития системы брендинга становится «управление смыслами», в процессе которого происходит их движение в социальном времени и социальном пространстве.

Когда появляются недопонимание или отторжение транслируемого смысла, действия социальных акторов, расположенных на «узлах» линий коммуникаций, выходят из-под контроля управляющего субъекта. Его авторитаризм в данном случае может привести к негативным результатам, так как им игнорируется самоценность компетенции и индивидуального опыта других участников процессов брендинга, при том что инновация всегда появляется из разногласия, предложения альтернативы, разумного компромисса. Стремление сохранить стабильность системы брендинга путем жесткого авторитарного управления может привести к отрицательным результатам еще и потому, что поначалу кажущиеся отрицательными с точки зрения их последствий действия социальных акторов, являющихся элементами системы, нередко имеют потенциал ее положительного развития.

Отвергнув авторитарный подход и проявив стремление оценить инновационный потенциал альтернативного предложения, управляющий субъект приобретает возможность эффективно реализовывать свою функцию, связанную с обеспечением, выработкой и имплементацией способов идентификации и интерпретации происходящего, как внутри системы (на микроуровне - в пределах компании, занимающейся брендингом, и на мезауровне - в связи с другими организациями, непосредственно вовлеченными в его процессы), так и за ее пределами (на макроуровне - в ее экологии: политической, экономической, социальной, культурной).

\section{ЗАКАЮЧЕНИЕ}

Так как практически невозможно уследить за всеми социальными акторами, вовлеченными в систему брендинга, предугадать их интенции и последствия воздействия на ее функционирование, интуиция управляющего социального актора - один из путей принятия им адекватного решения. Его искусство проявляется в способности усмотреть уникальность и перспективы изменений, обнаружить в системе брендинга рискогенные узды и, по возможности, точечно воздействовать на принадлежащих к ним социальных акторов, предопределяя траекторию развития события и таким образом реализуя свои цели, направленные на оптимизацию действия и развития системы. При этом управляющий субъект должен осознавать, что она никогда не будет в состоянии перманентной стабильности и должен быть готовым к неожиданной для него ригидности или активной негативной реакции на его действия социальных акторов, вовлеченных в брендинговый процесс.

\section{СПИСОК АИТЕРАТУРЫ}

Бариле, Н. (2015) Брендирование «я» в эпоху эмоционального капитализма. Эксплуатация «просьюмеров» от риторики double-bind к гегемонии исповеди // Аогос. Т. 25. № 3 (105). C. $138-161$.

Бауман, 3. (2008) Текучая современность : пер. с англ. СПб. : Питер. 240 с.

Керимов, Т. Х. (1998) Система // Современный философский словарь / под общей ред. В. Е. Кемерова. 2-е изд. Аондон, Франкфурт-на-Майне, Париж, Аюксембург, Москва, Минск : ПАНПРИНТ. 1064 с. С. $788-790$.

Кравченко, С. А. (2002) Играизация общества: контуры новой постмодернистской парадигмы // Общественные науки и современность. №6. С. 143-155. 
Цевитт, Т. (2001) Маркетинговая миопия // Классика маркетинга: сборник работ, оказавших наибольшее влияние на маркетинг / под ред. Ю. П. Кантурвского. СПб. : Питер. 752 с. C. $11-34$.

Парсонс, Т., Шилз, Э., Олдс, Аж. (2002) Ценности, мотивы и системы действия // Парсонс Т. О структуре социального действия / под общ. ред. В. Ф. Чесноковой, С. А. Белановского. М. : Академический проект. 880 с. С. 458-562.

Рожков, И. Я., Багаева, Т. А. (2012) Брендинг - метасистема социального управления продвижением объектов в конкурентной среде // Ученые записки Российского государственного социального университета. № 10. С. 88-95.

Федотова, А. Н. (2014) Социология рекламной деятельности. М. : Издание Московского университета. 456 с.

Федотова, $\Lambda$. Н. (2003) Социология массовых коммуникаций. СПб. : Питер. 400 с.

Шарков, Ф. И. (2012) Коммуникология: Социология массовой коммуникации. М. : Аашков и Ко. 320 с.

Шмитт, Б. (2001) Эмпирический маркетинг : пер. с англ. М. : ФАИР-ПРЕСС. 400 с.

Aaker, J. L. (1997) Dimensions of Brand Personality // Journal of Marketing Research. Vol. 34 (3). P. 347-354.

Borden, N. H. (1964) The Concept of the Marketing Mix // Journal of Advertising Research. Vol. 4. No. 2. P. 2-7.

Chernatony, L., de, Dall'Olmo, R. F. (1998) Modelling the components of the brand // European Journal of Marketing. Vol. 32. P. 1074-1090. DOI: 10.1108/03090569810243721

Franzen, G., Bouwman, M. (2001) The mental world of brands: Mind, Memory and Brand Success. Oxfordshire, World Advertising Research (WARC), Henley on Thames. 446 p.

Goodyear, M. (1996) Divided by a common language: diversity and deception in the world of global marketing // Journal of the Market Research Society. № 38. P. 105-122.

Hatch, M. J., Schultz, M. (1997) Relations between organizational culture, identity and image // European Journal of Marketing. Vol. 31 (5/6). P. 356-365.

Keller, K. L. (2003) Brand Synthesis: The Multidimensionality of Brand Knowledge // Journal of Consumer Research. Vol. 29. P. 395-600. DOI: 10.1086/346254

Muniz, A. M. J., O'Guinn, T. C. (2001) Brand Community // Journal of Consumer Research. Vol. 27. P. 412-432.

WPP. Thirty Years of Communications Services. Annual Report and accounts - 2014 (2015). London, WPP Group. 248 p.

Аата поступления: 08.07.2016 г.

INCREASING THE EFFICIENCY OF SOCIAL MANAGEMENT
IN BRANDING
T. L. BAHAEVA,
(TARAS SHEVCHENKO NATIONAL UNIVERSITY OF KYIV, UKRAINE)
I. YA. ROZHKOV
(MGIMO UNIVERSITY)

Branding has become an increasingly intensive sphere of activity. Branding communications are ever more widely implemented in different areas of life, while the high branding costs keep requiring optimization. The authors assume that due to uncertainty of outcomes and high risks in branding, this aim could be achieved by complementing traditional marketing approaches to branding management with the innovative ones based on contemporary social theory.

Our analysis of the existing body of Russian and Western research has shown it to be largely focused on managerial, behavioral, psychological and communicative aspects of branding. In almost all of these works, the marketing approach is prevalent while the use of the sociological approach is rather limited, which impedes a complex study of branding. 
Meanwhile, society is undergoing radical change which is impossible to ignore. To make branding relevant to the new state of the social environment, we suggest it should be construed as a social system passing through several phases in its development; a system capable of self-control and selfexpansion, featuring a multitude of social actors and prone to slipping out of control of the managing subject. At the same time, authoritarian control over the system stifles innovation and thus can bring about negative outcomes.

These factors have also predetermined the use of new managing principles in branding. Unlike the traditional ones, they combine linear and non-linear management and include pinpoint impact on high-risk elements of the system - - the social actors involved into the branding process.

Keywords: brand; branding; social system in branding; meaning; management of meaning; autopoiesis; self-expansion; self-control; intuition; pinpoint impact

\section{REFERENCES}

Barile, N. (2015) Brendirovanie «ia» v epokhu emotsional'nogo kapitalizma. Ekspluatatsiia «pros'iumerov» ot ritoriki double-bind k gegemonii ispovedi. Logos, vol. 25, no. 3 (105), pp. 138-161. (In Russ.)

Bauman, Z. (2008) Tekuchaia sovremennost'. St. Petersburg, Piter. 240 p. (In Russ.)

Kerimov, T. Kh. (1998) Sistema. In: Sovremennyi filosofskii slovar', ed. V. E. Kemerov. 2e ed. London, Frankfurt-na-Maine, Parizh, Liuksemburg, Moscow, Minsk, PANPRINT. 1064 p. Pp. 788-790. (In Russ.)

Kravchenko, S. A. (2002) Igraizatsiia obshchestva: kontury novoi postmodernistskoi paradigm. Obshchestvennye nauki i sovremennost', no. 6, pp. 143-155. (In Russ.)

Levitt, T. (2001) Marketingovaia miopiia. In: Klassika marketinga: sbornik rabot, okazavshikb naibol'shee vliianie na marketing: sb. rabot, okazavshikh naibol'shee vliianie na marketing, ed. Yu. P. Kanturvskii. St. Petersburg, Piter. 752 p. Pp. 11-34. (In Russ.)

Parsons, T., Shils, E. and Olds, J. (2002) Tsennosti, motivy i sistemy deistviia. In: Parsons T. O strukture sotsial' nogo deistviia, ed. V. F. Chesnokova and S. A. Belanovskii. Moscow, Akademicheskii proekt. 880 p. Pp. 458-562. (In Russ.)

Rozhkov, I. Ya. and Bagaeva, T. L. (2012) Brending - metasistema sotsial'nogo upravleniia prodvizheniem ob'ektov v konkurentnoi srede. Ucbenye zapiski Rossiiskogo gosudarstvennogo sotsial' nogo universiteta, no. 10, pp. 88-95. (In Russ.)

Fedotova, L. N. (2014) Sotsiologiia reklamnoi deiatel' nosti. Moscow, Izdanie Moskovskogo universiteta. 456 p. (In Russ.) Russ.)

Fedotova, L. N. (2003) Sotsiologiia massovykb kommunikatsii. St. Petersburg, Piter. 400 p. (In

Sharkov, F. I. (2012) Kommunikologiia: Sotsiologiia massovoi kommunikatsii. Moscow, Dashkov i $\mathrm{K}^{\mathrm{O}} .320$ p. (In Russ.)

Schmitt, B. (2001) Empiricheskii marketing. Moscow, FAIR-PRESS. 400 p. (In Russ.)

Aaker, J. L. (1997) Dimensions of Brand Personality. Journal of Marketing Research, vol. 34 (3), pp. 347-354.

Borden, N. H. (1964) The Concept of the Marketing Mix. Journal of Advertising Research, vol. 4, no. 2, pp. 2-7.

Chernatony, L., de and Dall'Olmo, R. F. (1998) Modelling the components of the brand. European Journal of Marketing, vol. 32, pp. 1074-1090. DOI: 10.1108/03090569810243721

Franzen, G. and Bouwman, M. (2001) The mental world of brands: Mind, Memory and Brand Success. Oxfordshire, World Advertising Research (WARC), Henley on Thames. 446 p.

Goodyear, M. (1996) Divided by a common language: diversity and deception in the world of global marketing. Journal of the Market Research Society, no. 38, pp. 105-122.

Hatch, M. J. and Schultz, M. (1997) Relations between organizational culture, identity and image. European Journal of Marketing, vol. 31 (5/6), pp. 356-365.

Keller, K. L. (2003) Brand Synthesis: The Multidimensionality of Brand Knowledge. Journal of Consumer Research, vol. 29, pp. 395-600. DOI: 10.1086/346254 
Muniz, A. M. J. and O'Guinn, T. C. (2001) Brand Community. Journal of Consumer Research, vol. 27, pp. 412-432.

WPP. Thirty Years of Communications Services. Annual Report and accounts - 2014 (2015). London, WPP Group. 248 p.

Submission date: 08.07.2016.

Багаева Татьяна Иеонидовна - кандидат социологических наук, докторант кафедры отраслевой социологии Киевского государственного университета им. Тараса Шевченко, Украина. Адрес: 01601, Украина. г. Киев, ул. Владимирская, д. 64/13. Тел.: +38 050 3522365. Эл. адрес: tbahaeva@bsca.com.ua

Рожков Игорь Яковлевич - доктор экономических наук, профессор кафедры связей с общественностью Московского государственного института (университета) международных отношений МИА России, заслуженный работник высшей школы РФ. Адрес: 119454, Россия, г. Москва, пр-т Вернадского, А. 76. Тел.: +7 (495) 434-93-68. Эл. адрес: rozhkov2@rambler.ru

Bahaeva Tatyana Leonidovna, Candidate of Sociology, Doctoral student, Department of Branch Sociology, Faculty of Sociology, Taras Shevchenko Kyiv National University. Postal address: 64/13 Volodimirovska St., 01601 Kyiv, Ukraine. Tel.: +38 050 3522365. E-mail: tbahaeva@bsca.com.ua

Rozhkov Igor Yakovlevich, Doctor of Economics, Professor, Department of Public Relations, Moscow State Institute of International Relations (University), Ministry of Foreign Affairs of Russian Federation; Honored Worker of Higher Education of the Russian Federation. Address: 119454, 76 Vernadskogo Prospekt, Moscow. Tel.: +7 (495) 434-93-68. E-mail: rozhkov2@rambler.ru 